\section{ON THE \\ IMPORTANCE OF APPLYING PRESSURE IN THE TREATMENT OF EXTENSIVE ABSCESSES.}

\author{
By SAMUEL SOLLY, EsQ., F.R.S., \\ SURGEON TO ST. THOMAS'S HOSPITAL.
}

I AM not aware how far the plan, which it is my object in this paper to advocate, is in general use or not; but $I$ am so convinced of its value, that on the risk of most of your readers being accustomed to this treatment, I shall venture to bring it forward. I refer to the careful application of pressure over the surface of extensive abscesses after their contents have been discharged, and the early disuse of the poultice and its congener, warm-water dressing. I always prefer cotton-wool to any other kind of pad, as it fits better with all irregularities of surface; and I find that a greater amount of deep pressure can be kept up by strips of plaster than by a roller. By these means the surfaces of the abscess are kept well in contact, they adhere together, and the discharge soon ceases. The following case is merely one amongst many that I could adduce, and it is interesting in connexion with the treatment of punctured wounds and purulent absorption. In this case of pyæmia, fortunately for my young friend, the matter was discharged into the cellular tissue of the axilla, and not into the lungs.

T. S__ was taken on the 1st of March, 1855, with general lassitude and pain of the limbs, with headache and much prostration. Three or four days previously, he had received a dissection wound in the left thumb; and, on the above date, the part was painful, with some redness and swelling below the nail; the pain gradually extended up the arm, without however there being any visible indications of lymphatic inflammation, but with nuch constitutional irritation, and great prostration of powers. On the 3rd there was pain and tenderness in the axilla, which gradually extended over almost the entire side; and, on the 5th, there was general superficial redness. The swelling, however, seemed localized to a space about three inches below the axilla, with a diameter of about three inches. I first saw the patient on the 6th, and ordered the application of six leeches, followed by linseed poultice; infusion of roses, one ounce; dilute sulphuric acid, fifteen minims; sulphate of quinine, two grains; syrup of ginger, one scruple; sulphate of magnesia, ten grains; every four hours. On the 8 th, there was a feeling of deep-seated and indistinct fluctuation at the site of the swelling. $\mathrm{Mr}$. South saw him with me and considered it advisable to make an opening into the swelling, which was accordingly done; no pus escaped, but about half an ounce of serum; and this continued to drain away, in small quantities, during the two following days; and, on the $9 \mathrm{th}$, a free discharge of pus commenced. On the 10th, there was distinct fluctuation about five inches below the first opening, a free incision was made, and some pus discharged; both these openings continued to discharge freely during the next five days, and with consider able relief to the patient; the pain was much less, and the general constitutional irritation also considerably abated during this time. Strong beef-tea and port wine was administered ad libitum. On the 15th it was evident that there was a large collection of pus, just above the hip; and, on a free opening being made, nearly a pint of pus escaped. A large poultice was kept continually applied all over the side, and the pus was gently pressed out twice a day. At this time, the two upper openings were found to communicate; and a probe passed into the lower one could be pushed withont difficulty for a considerable distance in either direction, so that the abscess extended from the axilla to the hip. There was free discharge of pus from all the openings, with dead cellular tissue, up to the 19th, when I ordered the poultice to be discontinued, and the whole side to be well padded with lint, and firm pressure kept up by means of broad strips of adhesive plaster, carried over the compresses. From the very commencement of this treatment the discharge of pus rapidly diminished; at the end of five days the two upper openings had quit a closed, and the intervening structures had, to a great recovered their healthy condition, there being tolerably firm adhesion of the opposed surfaces, which had been separated by the burrowing of the pus. The cavity of the lower abscess, which was of considerable size, also began rapidly to diminish, and at this time, March 26th, is apparently quite obliterated.

The patient's general health is rapidly improving; and he has been to the hospital again to-day.

March 31st, 1855.
ON SOME CASES OF

STRICTURE TREATED IN ST. THOMAS'S HOSPITAL ACCORDING TO THE PLAN RECOMMENDED BY MR. THOS. WAKLEY.

\author{
WITH REMARKS.
}

By WALTER TYRRELL, EsQ, HOUSE-STRGEON TO TEE MOSPITAL.

THIs mode of treating stricture, which has been very successful, was introduced into practice in this hospital, about two years ago, by Mr. Solly, who substituted a catgut bougie for Mr. Wakley's silver stylet. Within the last few months it has been adopted by Mr. South, Mr. Simon, and by myself, amongst the out-patients. The plan is simple, and consists in first pass ing a small catgut bongie, of some length, into the bladder, over which a gum-elastic tube is slipped and retained in the bladder, thus rendering the cure more rapid and certain than by the ordinary modes of dilatation. It would appear to be adapted to all forms of the disease, but has been found to be especially valuable in those cases of old-standing stricture complicated with false passages. As the cure depends, not upon the mere chance of hitting the right passage at certain intervals, but the stricture once passed by the smallest bougie, the cure is almost infallibly attained. It has also been used with success in cases of retention depending on spasmodic action. In short, its trial within the wards of this hospital has, so far, been attended with signal success.

The cases have chiefly occurred in the practice of Messrs. South and Solly, and are chosen from a number of successful cases as affording examples of its utility in various circum. stances.

CASE 1. - The first case is that of Joseph H-C, who applied at the surgery for relief owing to retention of urine. He had had some slight difficulty in passing his urine for the last three months, and having been drinking rather freely on the afternoon of his admission, he found himself on the same evening unable to void his urine. He seemed in much pain. The bladder was distended. Attempts were made for some time to pass the ordinary silver catheters, without success; and the patient's sufferings were a good deal increased by the continual introduction of instruments. At last one of the very fine catgut bougies was passed through the stricture, and over it a tube of somewhat larger size; immediate relief followed.

Several other cases of an equally successful nature have occurred in the surgery. The next case is one in which two strictures of eight years' standing were cured by the application of this apparatus.

CASE 2.-S. T_, aged forty-five, hawker, who has lived irregularly, has suffered from stricture for eight years, was admitted into George's ward under Mr. South. He has never been under treatment before, and passes his urine almost drop by drop. On admission, a stricture was found, situated about an inch and a balf from the orifice of the meatus urinarius, of great firmness; it did not admit the smallest silver instrument. Through this, with some difficulty, a small bougie was passed so as to admit of the discovery of another stricture further back. The apparatus was now had recourse to, and a very small catgut bougie passed into the biadder; and over this a No. 6 tube, with less pain than could have been expected from the passage of so large an instrument. This was fastened into the bladder; but the patient finding it uneasy, removed it in the night. It was again passed, and fastened in, the next day. It was retained in the bladder; and in less than a month from that time, he was discharged cured; and has continued to pass his urine in a full stream ever since.

In the next case, the patient had laboured under stricture for two years ; and, on admission into Abraham's ward, under Mr. Solly, was in the following condition :-

CASE 3.-R. T-, a man of apparently broken-down health, passes his urine literally drop by drop, and all attempts at micturition give rise to much straining, accompanied with sharp pains about the perinceum and loins. All attempts to introduce even the smallest-sized catheter failed; and it was not until some days after his admission that the smallest-sized catgut bougie was introduced; over this a No. 4 tube was passed; the patient suffered some little pain at the time; this, however, gradually subsided. The next day, by some means, the instrument slipped out, and was with some difficulty reintroduced. It was now kept in; and, in a few days, considerable discharge took place by the side of the catheter. He 